\title{
Supporting Information: Membrane/water partitioning and permeabilities of perfluoroalkyl acids and four of their alternatives and the effects on toxicokinetic behavior
}

Andrea Ebert ${ }^{1,2, *}$ and Flora Allendorf ${ }^{1}$, Urs Berger $^{3}$, Kai-Uwe Goss $^{1,4}$, and Nadin Ulrich ${ }^{1}$

${ }^{1}$ Department of Analytical Environmental Chemistry, Helmholtz Centre for Environmental Research -

UFZ, Permoserstrasse 15, D-04318 Leipzig, Germany

${ }^{2}$ Institute of Biophysics, Johannes Kepler University, Gruberstrasse 40, 4020 Linz, Austria

${ }^{3}$ Department of Analytical Chemistry, Helmholtz Centre for Environmental Research - UFZ,

Permoserstrasse 15, D-04318 Leipzig, Germany

${ }^{4}$ Institute of Chemistry, University of Halle-Wittenberg, Kurt-Mothes-Strasse 2, D-06120 Halle, Germany

* Corresponding author: andrea.ebert@ufz.de

\section{Table of contents}

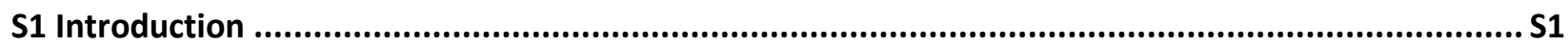

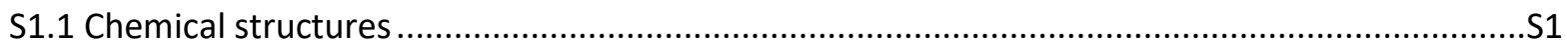

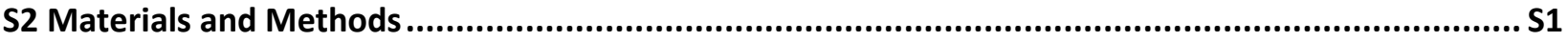

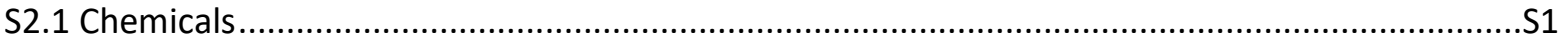

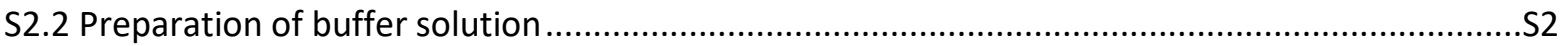

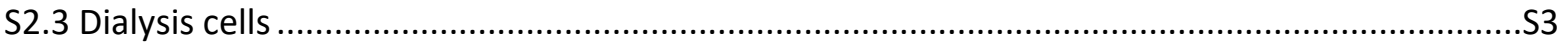

S2.4 Dependency of $K_{\mathrm{mem} / \mathrm{w}}$ on the measuring uncertainty of fraction bound................................S3

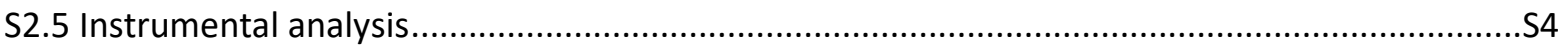

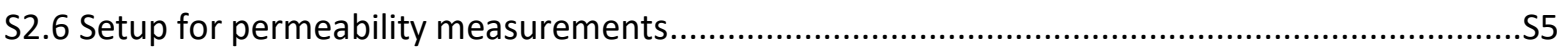

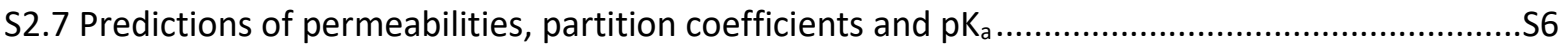

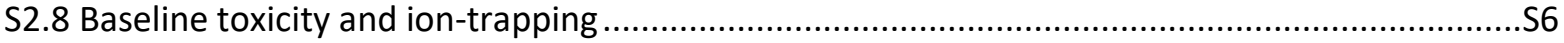

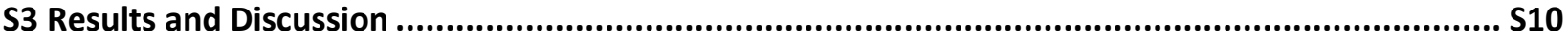

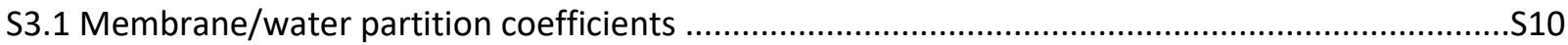

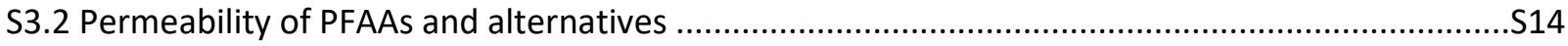

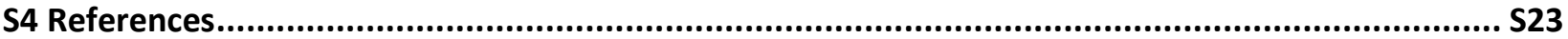




\section{S1 Introduction}

\section{S1.1 Chemical structures}<smiles>COC(=O)C(F)(OC(F)(F)C(F)(F)C(F)(F)F)C(F)(F)F</smiles>

HFPO-DA<smiles>O=C([O-])C(F)(F)C(F)OC(F)(F)C(F)(F)C(F)(F)OC(F)(F)F</smiles>

DONA<smiles>CC(=O)C(F)(F)C(F)(F)C(F)(F)C(F)(F)C(F)(F)C(F)(F)C(F)(F)F</smiles>

PFOA<smiles>CS(=O)(=O)C(F)(F)C(F)(F)OC(F)(F)C(F)(F)C(F)(F)C(F)(F)C(F)(F)C(F)(F)Cl</smiles>

9Cl-PF3ONS<smiles>O=S(=O)([O-])C1(F)C(F)(F)C(F)(F)C(F)(C(F)(F)C(F)(F)F)C(F)(F)C1(F)F</smiles>

PFECHS<smiles>CS(=O)(=O)C(F)(F)C(F)(F)C(F)(F)C(F)(F)C(F)(F)C(F)(F)C(F)(F)C(F)(F)F</smiles>

PFOS

Figure S1.1. The four alternatives to long-chain perfluoroalkyl acids included in this study. Top line: tetrafluoro-2(heptafluoropropoxy)-propanoate (HFPO-DA) and 4,8-dioxa-3H-perfluorononanoate (DONA), compared to perfluorooctanoate (PFOA). Bottom line: 9-chlorohexadecafluoro-3-oxanonane-1-sulfonate (9Cl-PF3ONS) and perfluoro-4-ethylcyclohexanesulfonate (PFECHS) compared to perfluorooctanesulfonate (PFOS). The production of PFECHS and $9 \mathrm{Cl}-\mathrm{PF} 30 \mathrm{NS}$ in fact goes back to the nineties. ${ }^{1-3}$ Both are included here, although they were not synthesized originally as a replacement for PFAAs.<smiles>CCCCCCCC/C=C\CCCCCCCC(=O)OCC(COP(=O)([O-])OCC[N+](C)(C)C)OC(=O)CCCCCCCCCCC</smiles>

Figure S1.2. Chemical structure of a typical phospholipid: 1-palmitoyl-2-oleoyl-glycero-3-phosphocholine (POPC). The hydrophilic head contains a phosphate group and the tail is composed of fatty acids of varying length. The displayed fatty acid composition of one saturated and one unsaturated long-chain fatty acid (palmitic acid C16:0 and oleic acid C18:1) is typical for eukaryotic membranes. ${ }^{4}$

\section{S2 Materials and Methods}

\section{S2.1 Chemicals}

Sodium dodecafluoro-3H-4,8-dioxanonanoate (DONA, correct abbreviation NaDONA), 2,3,3,3-tetrafluoro2-(1,1,2,2,3,3,3-heptafluoropropoxy-)propanoic acid (HFPO-DA/GenX), potassium 9chlorohexadecafluoro-3-oxanonane-1-sulfonate (9CI-PF3ONS, main component of F-53B), potassium perfluoro-4-ethylcyclohexanesulfonate (PFECHS) and a mixture of PFAA calibration standards (PFAC-MXB) and internal standards (MPFAC-MXA) were supplied by Wellington Laboratories (Ontario, Canada). 
Individual solutions of PFAAs were purchased separately, see Table S2.1.

Synthetic powder of 1-palmitoyl-2-oleoyl-glycero-3-phosphocholine (POPC) for the preparation of liposomes was supplied by Avanti Polar Lipids (Alabaster, Alabama, USA; >99\%). DPhPC (1,2-diphytanoylsn-glycero-3-phosphocholine) for the formation of free standing planar lipid bilayers was produced by Avanti Polar Lipids and provided by Merck (Darmstadt, Germany).

The buffers Hank's balanced salt solution (HBSS) and MOPS (3-morpholinopropane-1-sulfonic acid), as well as DMSO (dimethylsulfoxide), and potassium chloride $(\mathrm{KCl})$ were purchased from Sigma-Aldrich (Munich, Germany). Potassium persulfate was supplied by Merck (Darmstadt, Germany).

Table S2.1. Suppliers of individual PFAAs.

\begin{tabular}{llll}
\hline compound & abbreviation & company & purity \\
\hline \hline perfluorobutanoic acid & PFBA & Sigma Aldrich & $99 \%$ \\
perfluorohexanoic acid & PFHxA & Fluka & $>97 \%$ \\
perfluoroheptanoic acid & PFHpA & Sigma Aldrich & $99 \%$ \\
perfluorooctanoic acid & PFOA & ABCR & $>97 \%$ \\
perfluorononanoic acid & PFNA & Sigma Aldrich & $97 \%$ \\
perfluorodecanoic acid & PFDA & Fluka & $>97 \%$ \\
perfluoroundecanoic acid & PFUnDA & Sigma Aldrich & $95 \%$ \\
perfluorododecanoic acid & PFDoDA & Sigma Aldrich & $95 \%$ \\
perfluorobutanesulfonic acid & PFBS & Fluka & $>98 \%$ \\
perfluorohexanesulfonic acid & PFHxS & Fluka & $98 \%$ \\
perfluorooctanesulfonic acid & PFOS & Fluka & $98 \%$ \\
\hline
\end{tabular}

a purchased as a tetrabutylammonium hydroxide salt

${ }^{\mathrm{b}}$ purchased as a potassium salt

\section{S2.2 Preparation of buffer solution}

Hank's balanced salt solution (HBSS) was supplied as a powder from Sigma Aldrich (Munich, Germany). To mimic biological conditions ${ }^{5}$ sodium carbonate (Sigma Aldrich; $0.35 \mathrm{~g} / \mathrm{L}$ ) and TRIS (Roth, Karlsruhe; $1.21 \mathrm{~g} / \mathrm{L}$ ) were added and $\mathrm{pH}$ was adjusted to 7.4. $\mathrm{NaN}_{3}$ (Merck, Darmstadt, Germany) as an antimicrobial agent was added to the concentration of $0.3 \mathrm{~g} / \mathrm{L}$ at which no effects have been reported. ${ }^{5,6}$ 


\section{S2.3 Dialysis cells}

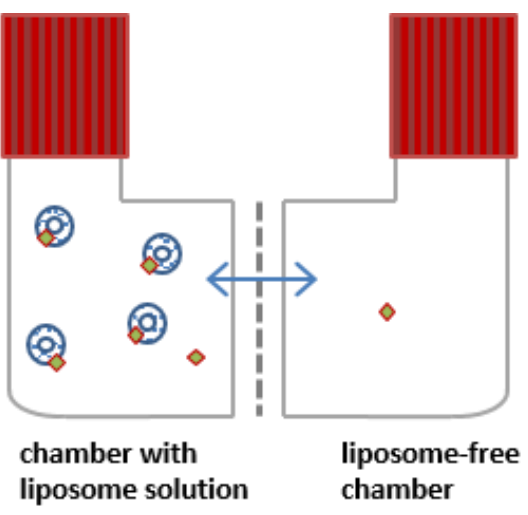

test cell

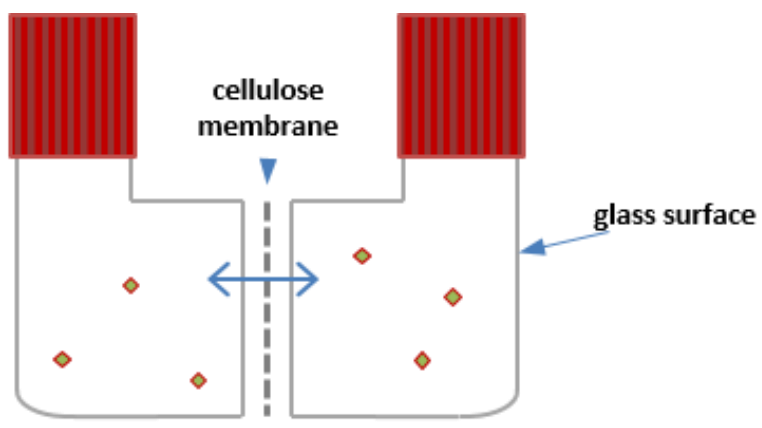

liposome-free chamber

liposome-free chamber

\section{reference cell}

$\diamond$ per-/polyfluorinated compound

Figure S2.3. Dialysis cell setup composed of two glass chambers separated by a cellulose membrane. The latter has a molecular cutoff of $12-14 \mathrm{kDa}$ and prevents the liposomes from permeating freely. There are two types of dialysis cells, test cells and reference cells. At the beginning of the experiment, liposome solution was added to one chamber while analyte solution was added to the other chamber. For reference cells, one chamber initially received only buffer while the other chamber received the analyte solution. Equilibrium was reached when the concentrations equalize in both chambers of the reference cells. For long-chain PFAAs such as PFDA, PFUnDA, PFOS, 9CI-PF3ONS and PFECHS the equilibration time was $96 \mathrm{~h}$, for all other compounds it was $72 \mathrm{~h}$.

\section{S2.4 Dependency of membrane/water partition coefficient $K_{\mathrm{mem} / \mathrm{w}}$ on the measuring uncertainty of fraction bound}

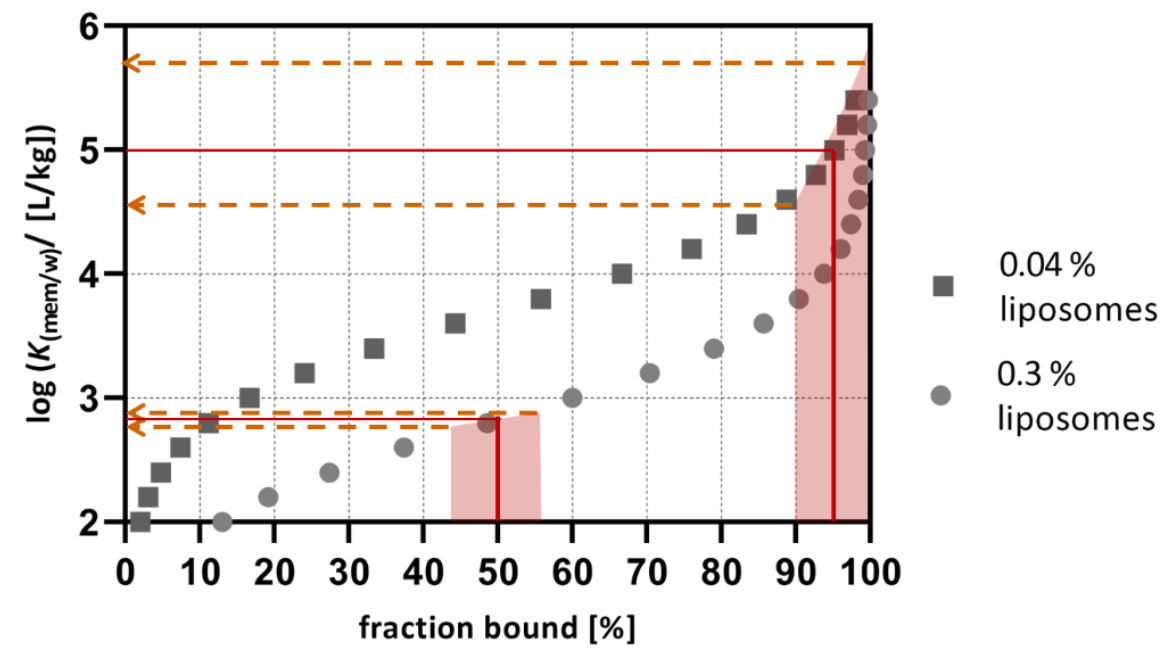

Figure S2.4. The relation between measuring uncertainty and fraction bound on the determination of the partition coefficient. To ensure the accuracy of the determined partition coefficient the fraction bound to the liposomes should be between $20-80 \%$. Below or above that fraction, small measuring uncertainties could have significant effects on the determined partition coefficient, since in this ranges partition coefficients alter drastically. 


\section{S2.5 Instrumental analysis}

For the analysis by UPLC-MS/MS, ammonium acetate $\left(\mathrm{NH}_{4} \mathrm{Ac}\right)$ in methanol and internal standard solution were added to all samples to a final concentration of $2 \mathrm{mM}$ and $1 \mathrm{ng} / \mathrm{mL}$, respectively. After injection, separation was achieved with the column ACQUITY UPLC BEH Shield C18 (1.7 $\mu \mathrm{m}$ particles; $2.1 \mathrm{~mm} \mathrm{x}$ $50 \mathrm{~mm}$ ). A "PFC isolator column" (Waters Corporation, Milford, USA) was used to retain and separate method blanks originating from the mobile phases or the HPLC-system. Water- and methanol based eluents contained $2 \mathrm{mM} \mathrm{NH}_{4} \mathrm{Ac}$ each. The detector operated in negative electrospray ionization mode $\left(\mathrm{ESI}^{-}\right)$and multi reaction monitoring mode (MRM). Instrumental parameters and MS/MS transitions are summarized in Tables S2.5.1.-2. Data acquisition, processing and analysis were done by the Water's proprietary software MassLynx (version 4.1). Quantification was achieved by an external linear calibration.

Table S2.5.1. LC gradient for the analysis of PFAAs/alternatives. Eluent A: $2 \mathrm{mM} \mathrm{NH}_{4} \mathrm{Ac}$ in Milli-Q water and Eluent B: $2 \mathrm{mM} \mathrm{NH}_{4} \mathrm{Ac}, 10 \%$ acetonitrile and $2.5 \%$ Milli-Q water in methanol.

\begin{tabular}{llll}
\hline time/ [min] & flow/ [mL/min] & \% A & \% B \\
\hline $\mathbf{0}$ & 0.4 & 90 & 10 \\
$\mathbf{0 . 5}$ & 0.4 & 90 & 10 \\
$\mathbf{5}$ & 0.4 & 0.1 & 99.9 \\
$\mathbf{7 . 3}$ & 0.4 & 0.1 & 99.9 \\
$\mathbf{7 . 3 1}$ & 0.4 & 90 & 10 \\
$\mathbf{9}$ & 0.4 & 90 & 10 \\
\hline
\end{tabular}


Table S2.5.2. MS/MS parameters for the analysis in $\mathrm{ESI}^{-}$mode of PFAAs/alternatives and for the corresponding internal standards. Retention time ( $\mathrm{rt}$ ), source sampling cone (cone), collision energy (CE), multi reaction monitoring (MRM) transitions, internal standard (IS), the experimental limit of quantification (LOQ) and limit of detection (LOD).

\begin{tabular}{|c|c|c|c|c|c|c|c|c|c|c|c|}
\hline compound & $\begin{array}{l}\mathrm{rt} / \\
\text { [min] }\end{array}$ & $\begin{array}{l}\text { cone/ } \\
{[\mathrm{V}]}\end{array}$ & $\begin{array}{l}\text { CE/ } \\
{[\mathrm{V}]}\end{array}$ & $\begin{array}{l}\text { MRM } \\
\text { transitions }\end{array}$ & $\begin{array}{l}\text { qualifier } \\
\text { transit- } \\
\text { ions }\end{array}$ & $\begin{array}{l}\text { internal } \\
\text { standard }\end{array}$ & $\begin{array}{l}\text { cone/ } \\
\text { [V] }\end{array}$ & $\begin{array}{l}\mathrm{CE} / \\
{[\mathrm{V}]}\end{array}$ & $\begin{array}{l}\text { IS MRM } \\
\text { transit- } \\
\text { ions }\end{array}$ & $\begin{array}{c}\text { LOQ/ } \\
\text { pg }\end{array}$ & $\begin{array}{c}\text { LOD/ } \\
\text { pg }\end{array}$ \\
\hline PFBA & 1.35 & 2 & 12 & $213>169$ & & ${ }^{13} C_{4}$ PFBA & 2 & 12 & $217>172$ & $2.5 \mathrm{E}-1$ & $7.5 \mathrm{E}-2$ \\
\hline PFHXA & 4.01 & 2 & 12 & $313>269$ & & ${ }^{13} \mathrm{C}_{2} \mathrm{PFH} \times \mathrm{A}$ & 2 & 12 & $315>270$ & $8.5 \mathrm{E}-2$ & $2.5 \mathrm{E}-2$ \\
\hline PFHpA & 4.43 & 2 & 12 & $363>319$ & & ${ }^{13} \mathrm{C}_{2} \mathrm{PFH} \times \mathrm{A}$ & 2 & 12 & $315>270$ & $6.8 \mathrm{E}-2$ & $2.0 \mathrm{E}-2$ \\
\hline PFOA & 4.73 & 2 & 12 & $413>369$ & & ${ }^{13} \mathrm{C}_{4} \mathrm{PFOA}$ & 2 & 12 & $417>372$ & 3.0E-1 & $9.0 \mathrm{E}-2$ \\
\hline PFNA & 4.99 & 2 & 12 & $463>419$ & & ${ }^{13} C_{5}$ PFNA & 2 & 12 & $468>423$ & $6.5 \mathrm{E}-2$ & $1.9 \mathrm{E}-2$ \\
\hline PFDA & 5.2 & 2 & 12 & $513>469$ & & ${ }^{13} \mathrm{C}_{2}$ PFDA & 2 & 12 & $515>470$ & 4.1E-2 & $1.2 \mathrm{E}-2$ \\
\hline PFUnDA & 5.4 & 2 & 12 & $563>519$ & & ${ }^{13} \mathrm{C}_{2} \mathrm{PF}$ UnDA & 2 & 12 & $565>520$ & 4.3E-2 & $1.3 \mathrm{E}-2$ \\
\hline PFDoDA & 5.8 & 2 & 12 & $613>570$ & & ${ }^{13} \mathrm{C}_{2}$ PFDoDA & 2 & 12 & $615>570$ & $1.2 \mathrm{E}-1$ & $3.7 \mathrm{E}-2$ \\
\hline PFBS & 3.65 & 30 & 30 & $299>80$ & $299>99$ & ${ }^{13} \mathrm{C}_{2} \mathrm{PFH} \times \mathrm{A}$ & 2 & 12 & $315>270$ & $6.1 \mathrm{E}-2$ & $1.8 \mathrm{E}-2$ \\
\hline PFHxS & 4.57 & 30 & 32 & $399>80$ & $399>99$ & ${ }^{18} \mathrm{O}_{2} \mathrm{PFHXS}$ & 30 & 32 & $403>103$ & $1.6 \mathrm{E}-2$ & $4.8 \mathrm{E}-3$ \\
\hline PFOS & 5.05 & 30 & 38 & $499>80$ & $499>99$ & ${ }^{13} \mathrm{C}_{4} \mathrm{PFOS}$ & 30 & 38 & $503>99$ & $1.1 \mathrm{E}-1$ & $3.4 \mathrm{E}-2$ \\
\hline DONA & 5.63 & 4 & 14 & $377>251$ & $377>85$ & ${ }^{13} \mathrm{C}_{3} \mathrm{HFPO}-\mathrm{DA}$ & 8 & 20 & $287>185$ & $7.5 E-3$ & $2.3 \mathrm{E}-3$ \\
\hline HFPO-DA & 5.27 & 8 & 20 & $285>185$ & $285>169$ & ${ }^{13} \mathrm{C}_{3} \mathrm{HFPO}-\mathrm{DA}$ & 8 & 20 & $287>185$ & $3.2 \mathrm{E}-1$ & $9.7 \mathrm{E}-2$ \\
\hline 9Cl-PF3ONS & 5.49 & 8 & 26 & $531>350$ & $531>83$ & ${ }^{13} \mathrm{C}_{8} \mathrm{PFOS}$ & 30 & 38 & $507>99$ & $2.3 \mathrm{E}-2$ & $7.0 \mathrm{E}-3$ \\
\hline PFECHS & 5.08 & 54 & 32 & $461>381$ & $461>99$ & ${ }^{13} \mathrm{C}_{8} \mathrm{PFOA}$ & 4 & 10 & $421>376$ & $3.3 \mathrm{E}-3$ & $1.0 \mathrm{E}-3$ \\
\hline
\end{tabular}

\section{S2.6 Setup for permeability measurements}

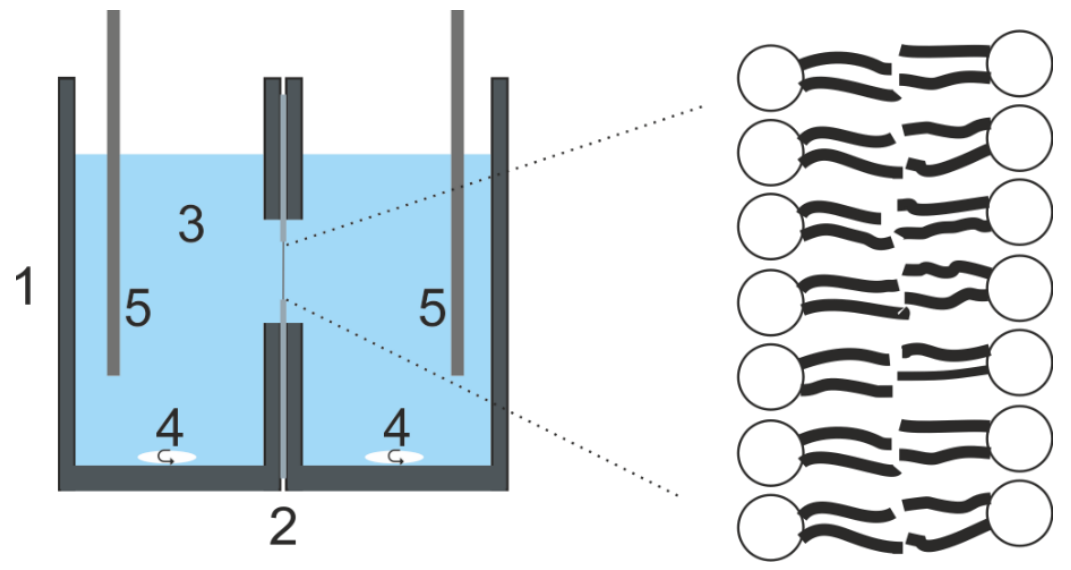

Figure S2.6. Schematic diagram of the setup for the permeability measurements. Two compartments of a Teflon chamber (1) are separated by a $25 \mu \mathrm{m}$ thick Teflon septum (2). The planar lipid bilayer is formed across a thin hole in the septum. Electrodes (5) are placed in the buffer solution (3). Voltage is applied across the membrane and the resulting current is measured. Magnetic stirrers (4) agitate the buffer solution to allow for a rapid mixing after addition of the chemical. The depiction is not up to scale and was adapted from Ebert et al. ${ }^{7}$ 


\section{S2.7 Predictions of permeabilities, partition coefficients and $\mathrm{pK}_{\mathrm{a}}$}

Table S2.7. Prediction methods and used parametrizations.

\begin{tabular}{lllll}
\hline parameter & species & tool & parametrization/version & used equations \\
\hline$K_{\mathrm{mem} / \mathrm{w}}$ & neutraltanion & COSMOmic & BP_TZVP_C30_1401 & \\
$K_{\mathrm{hd} / \mathrm{w}}$ & neutral & COSMOtherm & & \\
$K_{\mathrm{hd} / \mathrm{w}}$ & anion & BP_TZVPD_FINE_18 & $P_{\mathrm{n}}=K_{\mathrm{hd} / \mathrm{w}}{ }^{\mathrm{a}} \mathrm{D} / \mathrm{d}^{\mathrm{c}}$ \\
$P_{\mathrm{n}}$ & neutral & COSMOtherm & BP_TZVPD_FINE_18 & $P_{\text {ion }}=0.6^{*} K_{\mathrm{hd} / \mathrm{w}+4.8^{\mathrm{d}}}$ \\
$P_{\text {ion }}$ & anion & COSMOperm & BP_TZVP_18 & \\
$\mathrm{pK}_{\mathrm{a}}$ & & COSMOtherm & BP_TZVPD_FINE_18 & \\
pK $_{\mathrm{a}}$ & & Jchem for Office & 19.9.0.467 &
\end{tabular}

\footnotetext{
a Parametrization and membrane dipole potential were selected as validated by Bittermann et al. ${ }^{8}$ Reference membrane was POPC (Potential position: 17.891; width: 7.138; depth: $320 \mathrm{mV}$ ).

${ }^{b}$ COSMOtherm ${ }^{9}$ Version 18.02 (2018), Dassault Systèmes Deutschland GmbH, Leverkusen, Germany; http://www.3DS.com

${ }^{c}$ Calculation of membrane permeability in accordance with the solubility-diffusion model. The diffusion constant in the membrane center $D_{m}$ was predicted at $25^{\circ} \mathrm{C}$ from molecular weight $\mathrm{MW}$ using the formula $D_{m}=1 / 10^{*} D_{a q}=10^{-5.13-}$ ${ }^{0.453^{*} \log (\mathrm{MW})}$, see Avdeef et al. ${ }^{10}$ and Bittermann et al. ${ }^{11}$ for details. $D_{a q}$ is the diffusion constant in water. The thickness of the hexadecane-like part of the membrane was assumed to be $10 \AA$, as in Bittermann et al. ${ }^{11}$ ${ }^{\mathrm{d}}$ Correlation between the predicted hexadecane/water partition coefficient $K \mathrm{hd} / \mathrm{w}$ and ionic permeability for anions in DPhPC from Ebert et al. ${ }^{7}$

e JChem for Office (Excel) was used for pKa calculation in water at 25드. JChem for Office 19.9.0.467, 2019 ChemAxon (http://www.chemaxon.com)
}

\section{S2.8 Baseline toxicity and ion-trapping}

Baseline toxicity is assumed to occur once the concentration of a compound in the membrane amounts to about $200 \mathrm{mmol} / \mathrm{kg}_{\mathrm{mem}}$. Our calculations are done with this specific value, yet literature data range down to $50 \mathrm{mmol} / \mathrm{kgmem}^{12}$ This uncertainty will simply propagate with the same factor to our final result.

In principle, all species of a compound can contribute to this toxic effect. ${ }^{13}$ The relation between the concentration of species $i$ inside the membrane $c_{m e m, i}$ and the concentration of species $i$ in the water $c_{w, i}$ can be expressed by the membrane/water partition coefficient $K_{\mathrm{mem} / \mathrm{w}, i}$ of the species $i$ :

$$
K_{m e m / w, i}=\frac{c_{m e m, i}}{c_{w, i}}
$$

For a toxic effect, the sum of all $c_{m e m, i}$ over all species $i$ must be equal to roughly $200 \mathrm{mmol} / \mathrm{kg}_{\mathrm{mem}}$ : 


$$
\sum_{i} c_{m e m, i}=200 \mathrm{mmol} / \mathrm{kg}_{m e m}
$$

Summing over Eq. S1 this can be rearranged as:

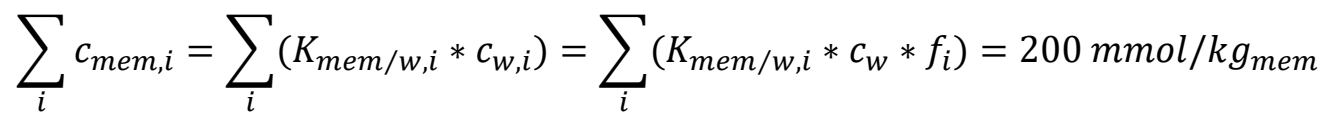

Where $\mathrm{f}_{i}$ is the fraction of species $i$ of the total freely dissolved concentration in water $\mathrm{c}_{\mathrm{w}}$ at aqueous $\mathrm{pH}$. Leading to the final expression for $\mathrm{c}_{\mathrm{w}}$ :

$$
c_{w}=\frac{200 \mathrm{mmol} / \mathrm{kg}_{\mathrm{mem}}}{\sum_{i}\left(K_{m e m} / \mathrm{w}, i\right.}
$$

Due to the low $\mathrm{pK}_{\mathrm{a}}$ of all acids analyzed in this work, the anionic species will strongly dominate $\left(\mathrm{f}_{\text {ion }} \approx 1\right)$ the partitioning into the membrane, and thus for the calculation of $c_{w}$ only the anionic $K_{\mathrm{mem} / \mathrm{w}}$ will be of relevance, and Eq. S4 simplifies to Eq. 4.

Yet, it is unclear whether baseline toxicity acts on the outer membrane or specific organelles (such as mitochondria) in the cytosol of the cell. Also, due to ion-trapping effects, the concentration inside the cell may be increased, which would increase toxicity in both cases. Ion-trapping occurs when the compound permeates as a neutral species through the membrane into the cell and deprotonates according to the local $\mathrm{pH}$. If this internal $\mathrm{pH}$ is higher than the external $\mathrm{pH}$ then internal dissociation of the acid will exceed the external dissociation. The gradient of the ionic species that builds up across the membrane cannot quickly be degraded due to the usually low anionic membrane permeability. To calculate the relation between the compound concentration outside and inside the cell, we will consider a steady-state situation in which there is no net compound flux across the membrane. The compound flux of the neutral species $\Phi_{\mathrm{n}}$ must be equal to the flux of anionic species $\Phi_{\text {ion }}$ in opposite direction:

$$
\Phi_{n}=-\Phi_{\text {ion }}
$$

The neutral flux driven by a concentration gradient $\Delta \mathrm{c}_{\text {neutral }}$ of the neutral species across the membrane can thus be expressed as:

$$
\Phi_{n, c y t \rightarrow e x t}=P_{n} * \Delta c_{n e u t r a l}=P_{n} *\left(c_{c y t} * f_{n, c y t}-c_{\text {ext }} * f_{n, \text { ext }}\right)
$$

Where $c_{\text {ext }}$ and $c_{c y t}$ are the total freely dissolved concentration and $f_{n, \text { ext }}$ and $f_{n, c y t}$ the neutral fractions outside the cell or inside the cytosol respectively. 
For the ionic flux, besides the chemical gradient, also an electrical potential $\Delta \mathrm{V}$ across the membrane (typically -60 mV across the outer cell membrane, negative inside) can be the driving force for permeation. This dependence is expressed by the Goldman-Hodgkin-Katz flux equation:

$$
\Phi_{\text {ion,cyt } \rightarrow \text { ext }}=P_{\text {ion }} * \frac{z F}{R T} \Delta V \frac{c_{c y t} * f_{\text {ion }, c y t}-c_{\text {ext }} * f_{\text {ion }, \text { ext }} * \exp \left(-\frac{z F}{R T} \Delta V\right)}{1-\exp \left(-\frac{z F}{R T} \Delta V\right)}
$$

Where $\mathrm{z}$ is the valence of the ion (-1), $\mathrm{F}$ is the Faraday constant, $\mathrm{R}$ the gas constant, and $\mathrm{T}$ the temperature in $\mathrm{K}(295 \mathrm{~K})$.

The fractions of neutral and anionic species are calculated depending on $\mathrm{pH}$ and $\mathrm{pK}_{\mathrm{a}}$ in accordance with the Henderson-Hasselbalch equation:

$$
\begin{gathered}
f_{n}=1 /\left(1+10^{p H-p K_{a}}\right) \\
f_{\text {ion }}=1 /\left(1+10^{-p H+p K_{a}}\right)
\end{gathered}
$$

Inserting Eq. S6 and S7 into Eq. S5, we arrive at the relation between the external and cytosolic concentration:

$$
\frac{c_{\text {ext }}}{c_{c y t}}=\frac{P_{n} * f_{n, c y t}+P_{\text {ion }} * f_{\text {ion }, c y t} * \frac{z F}{R T} \Delta V \frac{1}{1-\exp \left(-\frac{z F}{R T} \Delta V\right)}}{P_{n} * f_{n, \text { ext }}+P_{\text {ion }} * f_{\text {ion }, \text { ext }} * \frac{z F}{R T} \Delta V \frac{\exp \left(-\frac{z F}{R T} \Delta V\right)}{1-\exp \left(-\frac{z F}{R T} \Delta V\right)}}
$$

Assuming that the concentration in the cytosol is the one relevant for the toxic effect, we can express $\mathrm{c}_{\text {cyt }}$ by Eq. 4 , and thus Eq. 5 shows $c_{\text {ext }}$ in dependence of $K_{\text {mem/w. }}$. Cext would thus reflect the effective concentration that needs to be applied outside (freely dissolved concentration) to arrive at a toxic concentration in the cytosol.

For Eq. 5 two different extreme cases can be discussed: 
1. In case of dominating neutral permeation $\left(P_{n} * f_{n} \gg P_{\text {ion }} * f_{\text {ion }}\right)$, the expression simplifies to:

$$
c_{\text {ext }}=\frac{P_{n} * f_{n, c y t}}{P_{n} * f_{n, \text { ext }}} * \frac{200 \mathrm{mmol} / \mathrm{kg}_{\mathrm{mem}}}{K_{\mathrm{mem} / \mathrm{w}}}
$$

Eq. S11 corresponds to the conventional ion-trapping model, where ionic permeability is simply neglected, and neutral concentration is equal on both sides of the membrane.

2. In case of dominating anionic permeability $\left(P_{\text {ion }} * f_{\text {ion }} \gg P_{n} * f_{n}\right)$, the concentrations will distribute across the membrane according to the Nernst potential:

$$
c_{\text {ext }}=\frac{f_{\text {ion,cyt }}}{f_{\text {ion,ext }}} \exp \left(\frac{z F}{R T} \Delta V\right) * \frac{200 \mathrm{mmol} / \mathrm{kg}_{\text {mem }}}{K_{\text {mem } / \mathrm{w}}}
$$




\section{S3 Results and Discussion}

\section{S3.1 Membrane/water partition coefficients}

Table S3.1.1. Number of perfluorinated carbons, compound name, and experimental logarithmic membrane/water partition coefficients ( $\log K_{\mathrm{mem}} \mathrm{w}$ ) with standard deviation SD, and log $K_{\mathrm{mem}} \mathrm{w}$ predicted using COSMOmic. See also Table S2.6 for parametrization.

\begin{tabular}{llll}
\hline $\begin{array}{l}\text { number of } \\
\text { perfluorinated } \\
\text { carbons }\end{array}$ & compound & $\log \left(\boldsymbol{K}_{\mathrm{mem} / \mathrm{w} /[\mathrm{L} / \mathrm{kg}])^{\mathrm{a}}}\right.$ & $\log \left(\boldsymbol{K}_{\mathrm{mem} / \mathrm{w} /[\mathrm{L} / \mathrm{kg}])}\right.$ \\
\hline PFCAs & & experimental & predicted \\
\hline \hline 3 & PFBA & $<1.7$ & 3.17 \\
5 & PFHXA & $2.32 \pm 0.08$ & 3.48 \\
6 & PFHpA & $2.91 \pm 0.06$ & 3.63 \\
7 & PFOA & $3.52 \pm 0.08$ & 3.93 \\
8 & PFNA & $4.25 \pm 0.04$ & 4.30 \\
9 & PFDA & $4.82 \pm 0.11$ & 4.64 \\
10 & PFUnDA & $4.54 \pm 0.30$ & 5.06 \\
\hline & HFPO-DA & $2.41 \pm 0.13$ & 3.5 \\
& DONA & $3.03 \pm 0.07$ & 3.77 \\
\hline PFSAs & & & \\
\hline \hline 4 & PFBS & $2.86 \pm 0.06$ & 3.51 \\
6 & PFHXS & $4.13 \pm 0.05$ & 3.93 \\
8 & PFOS & $4.89 \pm 0.30$ & 4.69 \\
\hline 8 & $9 C 1-P F 3 O N S$ & $5.14 \pm 0.03$ & 5.15 \\
8 & PFECHS & $4.53 \pm 0.05$ & 4.01 \\
\hline
\end{tabular}

\footnotetext{
${ }^{a} \pm$ standard deviation of six measurements (three measurements on two days).
} 
Table S3.1.2. Experimental logarithmic membrane/water partition coefficients (log $K$ mem/w (with $K$ in $\mathrm{L}$ water/kg membrane)) of a series of perfluoroalkyl acids and four of their alternatives. Fraction bound ( $f_{\text {bound }}$ ), concentration of liposomes (Clip).

\begin{tabular}{|c|c|c|c|c|c|}
\hline $\begin{array}{l}\text { number of } \\
\text { perfluorinated } \\
\text { carbons }\end{array}$ & compound & $\begin{array}{l}\log \left(K_{\text {mem } / w} /\right. \\
[\mathrm{L} / \mathrm{kg}])^{\mathrm{a}}\end{array}$ & $\mathbf{f}_{\text {bound }}{ }^{\mathrm{a}, \mathrm{b}}$ & $\begin{array}{l}\text { recovery (incl. } \\
\text { extracts) }\end{array}$ & $\mathrm{C}_{\text {lip }} /[\mathrm{g} / \mathrm{L}]$ \\
\hline \multicolumn{6}{|l|}{ PFCAs } \\
\hline 3 & PFBA & $<1.7^{c}$ & & & \\
\hline 5 & PFHXA & $2.32 \pm 0.08$ & $30 \% \pm 4 \%$ & $100 \%$ & $4.0 \mathrm{E}+00$ \\
\hline 6 & PFHpA & $2.91 \pm 0.06$ & $45 \% \pm 3 \%$ & $93 \%$ & $2.0 \mathrm{E}+00$ \\
\hline 7 & PFOA & $3.52 \pm 0.08$ & $46 \% \pm 4 \%$ & $93 \%$ & $5.0 \mathrm{E}-01$ \\
\hline 8 & PFNA & $4.25 \pm 0.04$ & $65 \% \pm 2 \%$ & $92 \%$ & 2.0E-01 \\
\hline 9 & PFDA & $4.82 \pm 0.11$ & $63 \% \pm 6 \%$ & $94 \%$ & $5.0 \mathrm{E}-02$ \\
\hline \multirow[t]{3}{*}{10} & PFUnDA $^{d}$ & $4.54 \pm 0.30$ & $63 \% \pm 15 \%$ & $32 \%(95 \%)$ & $1.0 \mathrm{E}-01$ \\
\hline & HFPO-DA ${ }^{e}$ & $2.41 \pm 0.13$ & $35 \% \pm 6 \%$ & $100 \%$ & $4.0 \mathrm{E}+00$ \\
\hline & $\mathrm{DONA}^{\mathrm{e}}$ & $3.03 \pm 0.07$ & $36 \% \pm 3 \%$ & $92 \%$ & $1.0 \mathrm{E}+00$ \\
\hline \multicolumn{6}{|l|}{ PFSAs } \\
\hline 4 & PFBS & $2.86 \pm 0.06$ & $59 \% \pm 3 \%$ & $101 \%$ & $4.0 \mathrm{E}+00$ \\
\hline 6 & PFHxS & $4.13 \pm 0.05$ & $57 \% \pm 3 \%$ & $102 \%$ & $2.0 \mathrm{E}-01$ \\
\hline 8 & PFOS $^{d}$ & $4.89 \pm 0.30$ & $55 \% \pm 17 \%$ & $87 \%(104 \%)$ & 1.0E-02 \\
\hline 8 & $9 \mathrm{Cl}-\mathrm{PF} 3 \mathrm{ONS} \mathrm{d}^{\mathrm{d}}$ & $5.14 \pm 0.03$ & $52 \% \pm 2 \%$ & $87 \%(110 \%)$ & $5.0 \mathrm{E}-03$ \\
\hline 8 & PFECHS & $4.53 \pm 0.05$ & $35 \% \pm 2 \%$ & $92 \%$ & $1.0 \mathrm{E}-02$ \\
\hline
\end{tabular}

\footnotetext{
a \pm standard deviation of six measurements (three measurements on two days).

${ }^{b}$ Fraction bound represents the mass of compound that is bound to the membrane divided by the total available mass of compound $\left(\mathrm{m}_{i, \mathrm{mem}} / \mathrm{m}_{i, \text { tot }}\right)$.

c We were not able to determine log $K_{\mathrm{mem} / \mathrm{w}}$ accurately for PFBA as the shortest chain compound since the required concentration of liposomes $(>10 \mathrm{~g} / \mathrm{L}$ ) was above the maximal concentration which can be used in the extruder.

${ }^{d}$ Compounds sorbed substantially to the glass surface of the dialysis cells. For total mass balance, an extraction step with methanol was included and the partition coefficient was calculated with the mass that was not adsorbed to glass surface. e HFPO-DA and DONA are not fully fluorinated, therefore no number of perfluorinated carbons is assigned.
} 


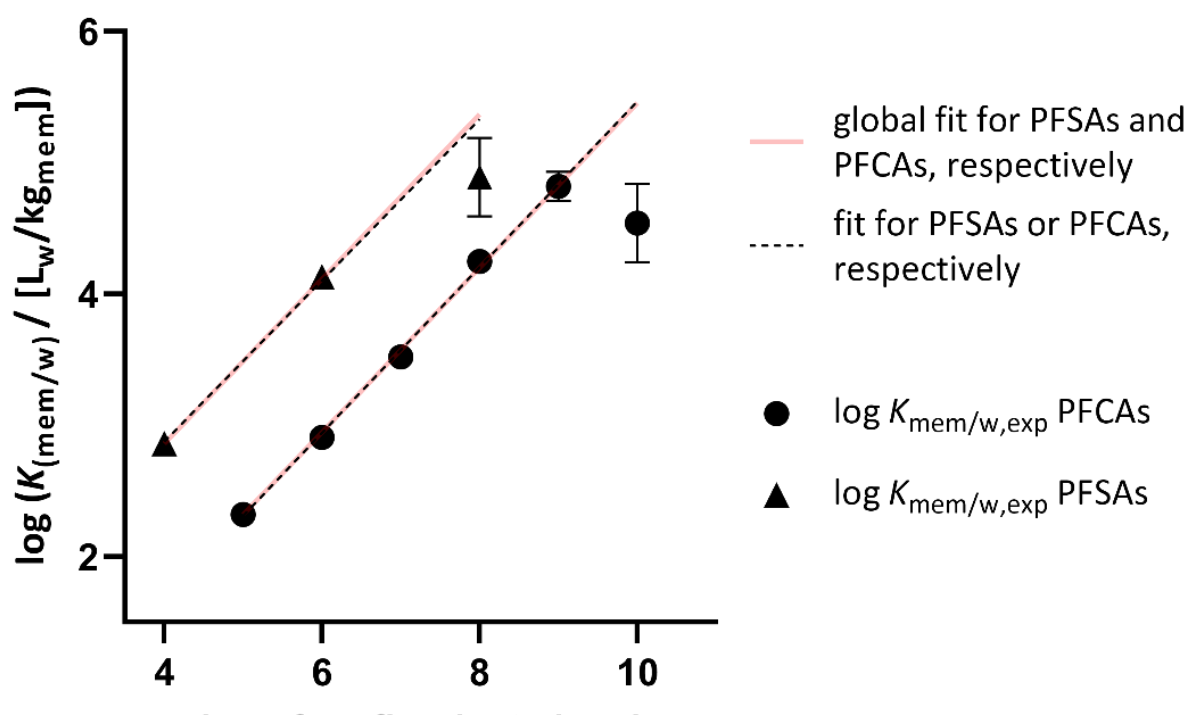

number of perfluroinated carbons

Figure S3.1.3. Logarithmic experimental membrane/water partition coefficients $K$ mem/w of PFCAs and PFSAs plotted against their number of perfluorinated carbons. The slopes depict the rate of increase in $K_{\mathrm{mem}} / \mathrm{w}$ per perfluorinated carbon of PFCAs and PFSAs. The slopes deducted from single fits were 0.63 log units per carbon for PFCAs and 0.61 for PFSAs. The slope deducted from a global fit (minimized RMSE for identical slopes for both data-series) was 0.63 $\log$ units per carbon, the intercepts were -0.81 and 0.36 respectively. The fit for PFSAs is therefore shifted to higher $\log K_{\mathrm{mem} / \mathrm{w}}$ by $1.17 \log$ units. All fits were weighted by the standard deviations. Fits were performed using Igor Pro (WaveMetrics, Lake Oswego, OR).

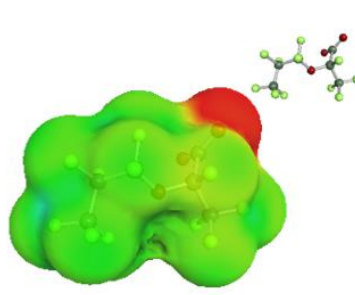

HFPO-DA

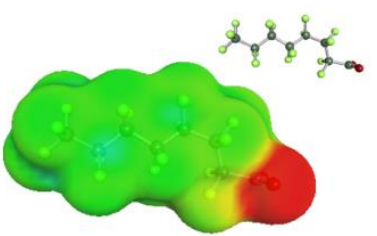

PFOA

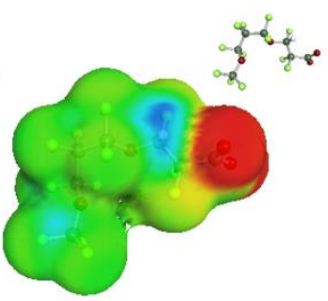

DONA

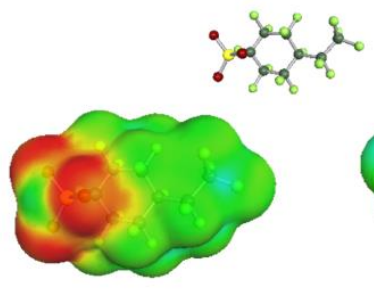

PFECHS

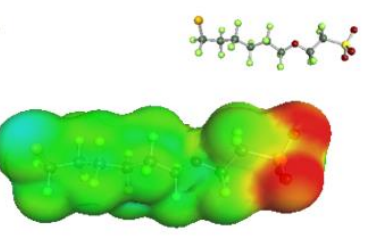

9Cl-PF3ONS

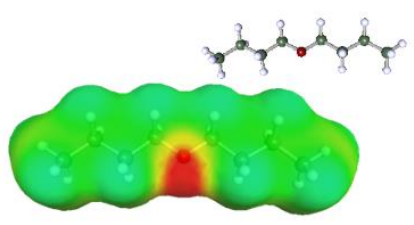

Di- $\boldsymbol{n}$-butylether

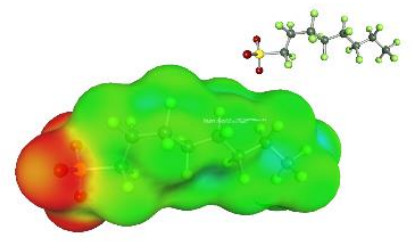

PFOS

Figure S3.1.4. Electron surface charge densities (sigma surfaces) of the investigated alternatives compared to the sigma surfaces of PFOA, PFOS and Di- $n$-butylether calculated by COSMOconf/TURBOMOLE software ${ }^{14,15}$. The surface charge density is color-coded: red: negative charge density (acidic), green: neutral, blue: positive charge density (basic). Figure adapted from Allendorf et al. ${ }^{16}$ 


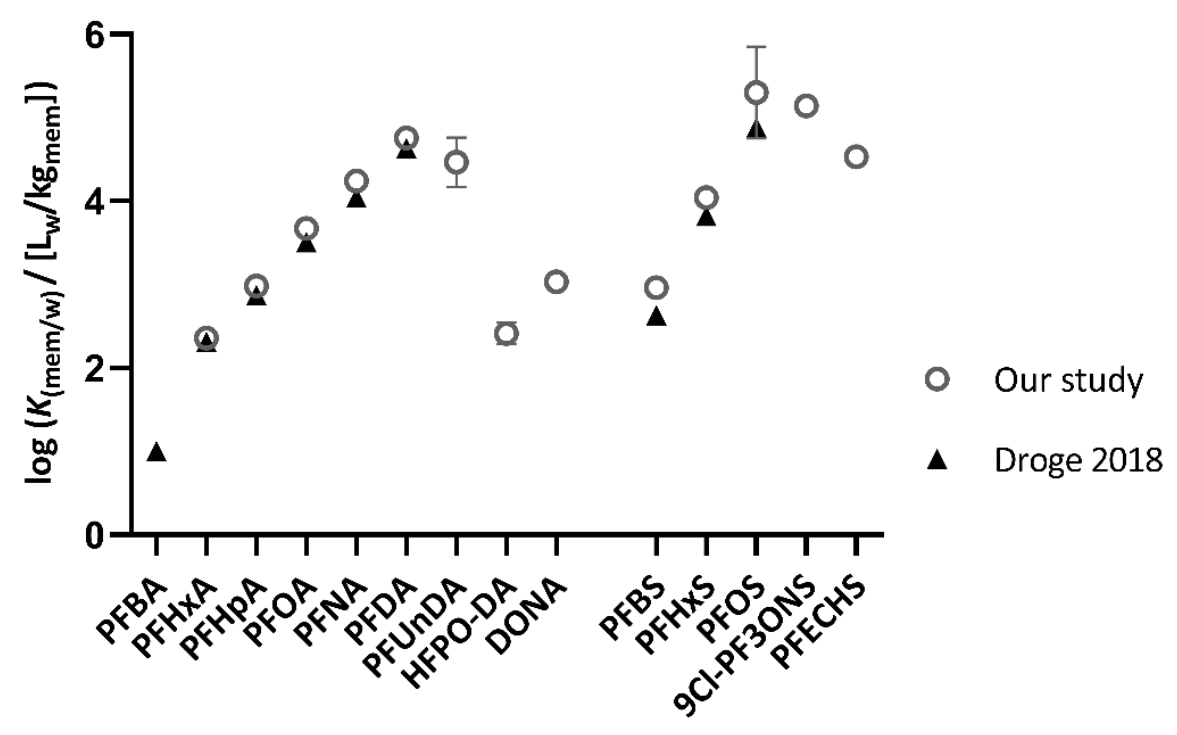

Figure S3.1.5. Comparison of the logarithmic membrane/water partition coefficients of the present study to the log $K_{\mathrm{mem} / \mathrm{w}}$ reported by Droge ${ }^{12}$ using Solid-Supported Phospholipid Bilayers (SSLM) for a similar series of PFAAs. Error bars of standard deviations are partly covered by symbols of data points. 


\section{S3.2 Permeability of PFAAs and alternatives}

Table S3.2.1. Compound name, experimental anionic permeability $P_{\text {ion }}$ with standard deviation, permeabilities of the anionic $P_{\text {ion }}$ and neutral $P_{\mathrm{n}}$ species predicted either using COSMOtherm (from hexadecane/water partition coefficient $\mathrm{K}_{\mathrm{hd} / \mathrm{w}}$ or COSMOperm respectively, $\mathrm{pK}_{\mathrm{a}}$ predicted using COSMOtherm and Jchem.

\begin{tabular}{|c|c|c|c|c|c|c|c|}
\hline & $\begin{array}{l}\log \left(P_{\text {ion }} /\right. \\
[\mathrm{cm} / \mathrm{s}])\end{array}$ & $\log \left(P_{i}\right.$ & $[\mathrm{cm} / \mathrm{s}])$ & $\log (P$ & $\mathrm{m} / \mathrm{s}])^{\mathrm{a}}$ & $\mathrm{pK}_{\mathrm{a}}^{\mathrm{b}}$ & \\
\hline & experimental & predic & & predic & & predicted & \\
\hline PFCAs & & $\begin{array}{l}\text { from } \\
K_{h d / w}\end{array}$ & cosMOperm & $\begin{array}{l}\text { from } \\
K_{\text {hd/w }}\end{array}$ & COSMOperm & cosmotherm & JChem $^{\mathrm{c}}$ \\
\hline PFBA & $N D^{d}$ & -8.82 & -10.42 & -0.29 & 0.62 & 0.40 & 1.07 \\
\hline PFHXA & ND & -7.74 & -8.71 & 1.10 & 1.36 & 0.61 & -0.78 \\
\hline PFHpA & ND & -7.40 & -8.15 & 1.85 & 1.64 & 0.63 & -2.29 \\
\hline PFOA & $-6.19 \pm 0.04$ & -6.89 & -7.45 & 2.55 & 1.65 & 0.55 & -4.20 \\
\hline PFNA & $-5.79 \pm 0.03$ & -6.49 & -6.77 & 3.25 & 1.79 & 0.72 & -6.51 \\
\hline PFDA & ND & -6.07 & -6.23 & 3.94 & 1.69 & 0.31 & -5.20 \\
\hline PFUnDA & ND & -5.60 & -5.64 & 4.63 & 1.61 & 0.36 & -5.20 \\
\hline PFDoDA & $-4.6^{e} \pm 0.3$ & -5.25 & -5.11 & 5.33 & 1.81 & 0.85 & -5.20 \\
\hline HFPO-DA & $-6.68 \pm 0.12^{f}$ & -6.92 & -7.83 & 1.39 & 1.34 & 1.10 & -0.77 \\
\hline DONA & ND & -6.98 & -7.89 & 2.09 & 1.49 & 0.98 & -1.39 \\
\hline PFSAs & & & & & & & \\
\hline PFBS & $-6.68 \pm 0.03$ & -6.56 & -6.41 & -0.13 & 0.94 & -5.70 & -3.31 \\
\hline PFHxS & $-5.37 \pm 0.02$ & -5.61 & -4.85 & 1.17 & 1.55 & -5.70 & -3.32 \\
\hline PFOS & $-4.26 \pm 0.05$ & -4.74 & -3.58 & 2.64 & 1.60 & -5.70 & -3.32 \\
\hline 9Cl-PF3ONS & $-4.12 \pm 0.03$ & -4.26 & -3.01 & 3.26 & 1.36 & -5.80 & -3.24 \\
\hline PFECHS & $-4.30 \pm 0.01$ & -4.76 & -3.38 & 1.51 & 1.48 & -4.20 & -3.11 \\
\hline
\end{tabular}

\footnotetext{
${ }^{\text {a }}$ For rather high membrane permeabilities $(>10 \mathrm{~cm} / \mathrm{s}$ ), the prediction based on the correlation to $\mathrm{Khd} / \mathrm{w}$ (see details in Table S2.6) and the prediction via COSMOperm differ for some compounds by several orders of magnitude. The correlation tends to overestimate membrane permeability, while COSMOperm tends to rather underestimate membrane permeability. We believe this to be caused by the different approaches of calculation: The correlation to $K_{\mathrm{hd} / \mathrm{w}}$ is based on the assumption that the membrane core is the main barrier for permeation. Thus, if for very hydrophobic compounds the membrane head groups became limiting, this method would overestimate permeability. On the other hand, COSMOperm considers the full membrane to calculate the permeation resistance. Yet, the permeation of the ionic species through the water layers adjacent to the membrane (unstirred water layer: there, transport is dominated by diffusion in water) and subsequent association according to the local $\mathrm{pH}$ will facilitate neutral permeation through the unstirred water layer. This facilitated transport should not have a sharp stop at the water/membrane interfaces, but may still reach into the outer membrane layers. As the resistance in these outer layers would thus be circumvented, a consideration of the full membrane could underestimate membrane permeability. The actual membrane permeability should thus lie somewhere in between these two values.
} 
${ }^{\mathrm{b}}$ Predicted using COSMOtherm or JChem respectively (see details in Table SI-2.6).

${ }^{c}$ The extreme differences in predicted $\mathrm{pK}_{\mathrm{a}}$ for very similar compounds such as PFHxA and PFNA let us assume that JChem is out of its applicability domain for PFAS, as they should be structural outliers to the training data. We will therefore in this work use the value predicted via COSMOtherm, an ab initio method.

${ }^{\mathrm{d}} \mathrm{ND}$ : no data; Compounds were selected for measurement to represent PFCAs, PFSAs, as well as alternatives.

e The initially determined value of $-4.99 \pm 0.03 \log$ units (only valid if the total added concentration equals the freely dissolved concentration) was corrected for analytical uncertainty of the quantification and for adsorption effects. Measurements showed that about $50 \%$ to $80 \%$ of the added PFDoDA adsorbed to the Teflon chambers, which corresponds to a reduction of the freely dissolved concentration. Corrected permeabilities range from -4.9 to -4.3 log units. This range is stated here, instead of the standard deviation stated for all other compounds.

${ }^{f}$ When measuring HFPO-DA, problems with membrane stability constricted our measured concentration range to relatively (in respect to membrane permeability) low concentrations $(<0.1 \mathrm{mM})$ and thus a low electrical signal. Although the measurement was therefore repeated on 6 different membranes, the resulting $P_{\text {ion }}$ is still less reliable than the other stated values. 


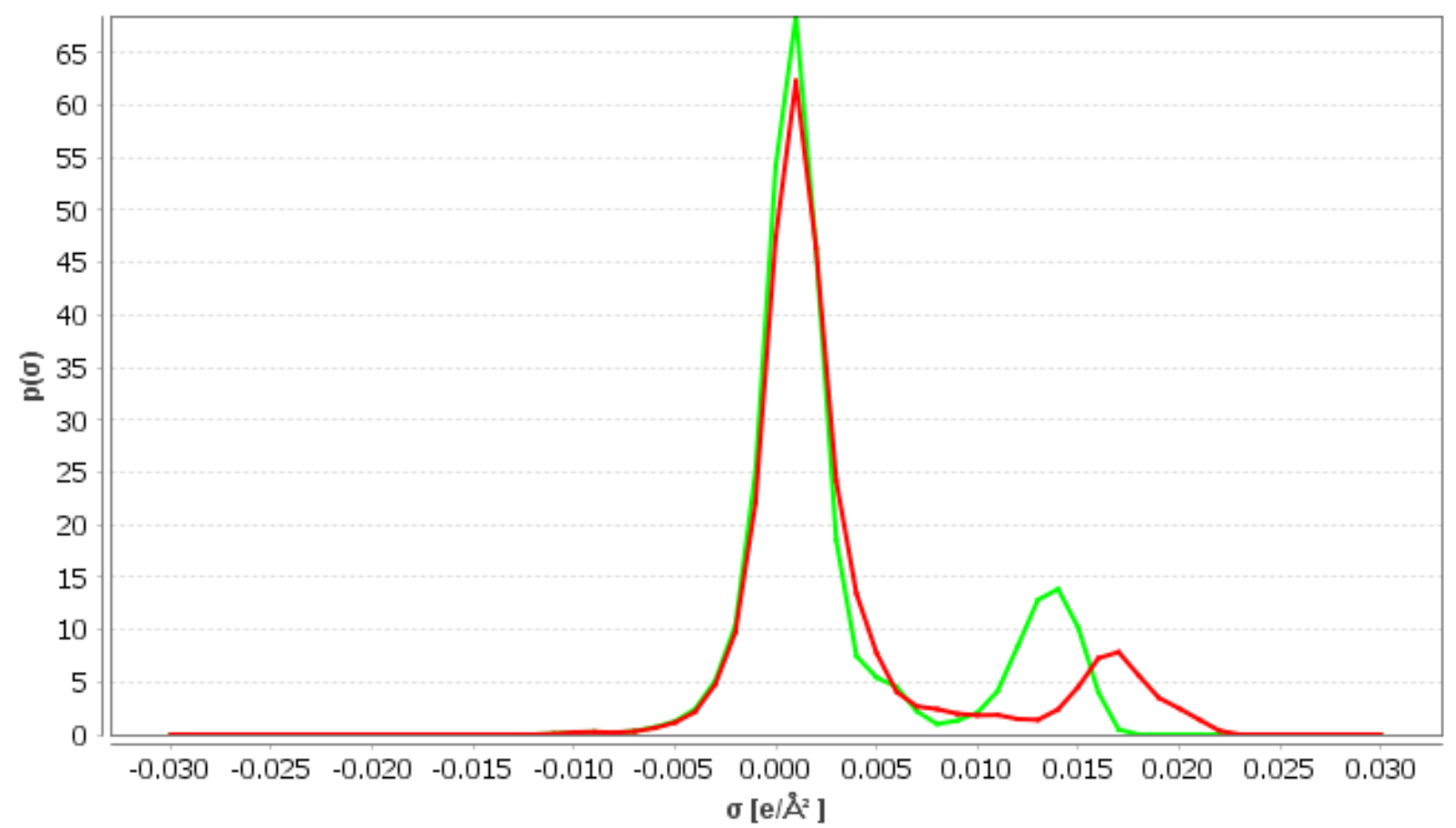

Figure S3.2.2. Sigma Profile of PFNA (red) and PFOS (green) anion visualized by the software COSMOtherm. It depicts the relative amount of surface with a specific charge density $\sigma\left[\mathrm{e} / \AA^{2}\right]$. Note that a positive COSMO charge density represents a negative molecular charge. The local maximum at the right that represents the charge densities of the head group is shifted to lower values for the sulfonate in comparison to the carboxylate head group.
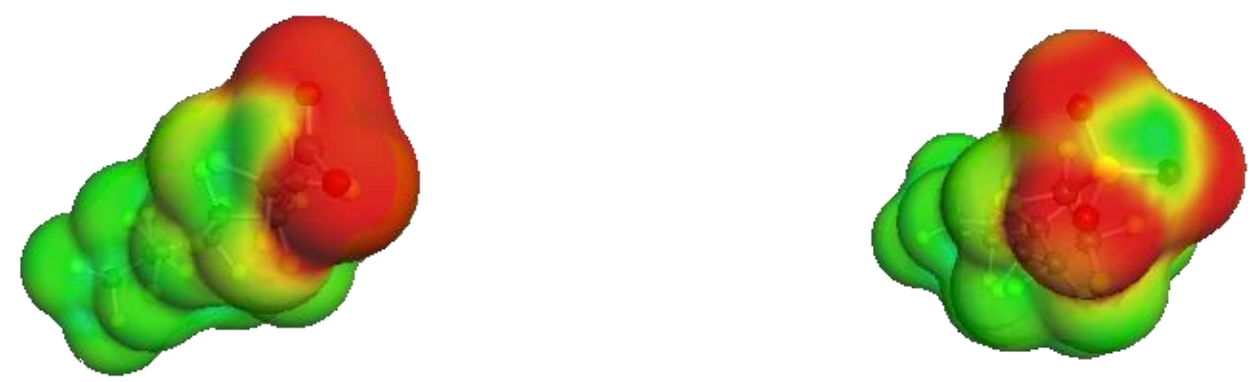

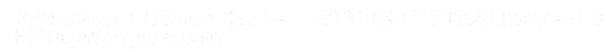

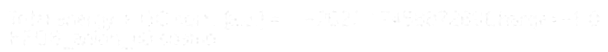

Figure S3.2.3. Sigma surfaces for PFNA (left) and PFOS (right). The red part represents a negative molecular surface charge density, while the green part is neutral. The darker the red color, the higher the charge density. The charge is more broadly distributed for PFOS, thus charge density is lower. 


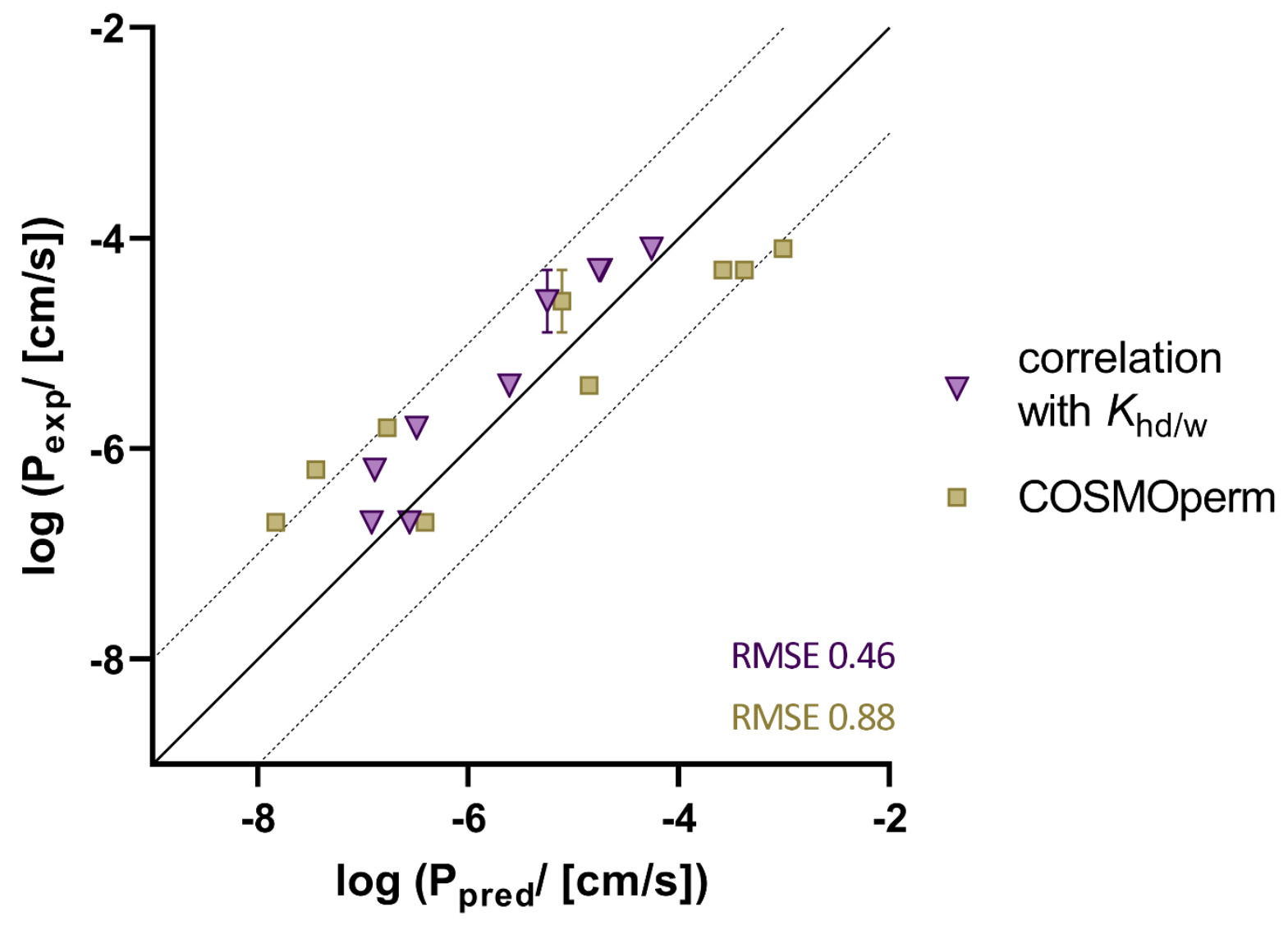

Figure S3.2.4. Experimental logarithmic anionic permeability plotted against the predicted anionic permeability, using either the correlation between the permeability and the respective hexadecane/water partition coefficient $K_{\mathrm{hd} / \mathrm{w}}$, or COSMOperm. Details on the prediction methods are stated in Table S2.6. RMSE calculations were performed using Igor Pro (WaveMetrics, Lake Oswego, OR). 
Table S3.2.5. Compound abbreviation, hexadecane/water partition coefficients $K_{\mathrm{hd} / \mathrm{w}}$ for the anionic and neutral species, predicted using COSMOtherm, molecular weight $\mathrm{MW}$, diffusion constant $\mathrm{D}_{\mathrm{m}}$ in the membrane core predicted from molecular weight, neutral fraction at $\mathrm{pH} 7.4$, and the relation between ionic and effective neutral permeability (normalized by the respective fractions).

\begin{tabular}{|c|c|c|c|c|c|c|c|}
\hline \multirow{2}{*}{$\begin{array}{l}\text { compound } \\
\text { PFCAs }\end{array}$} & \multicolumn{2}{|c|}{$\log \left(K_{h d / w} /\left[L_{w} / L_{h d}\right]\right)$} & \multirow[t]{2}{*}{$\begin{array}{l}\mathrm{MW} / \\
\text { [g/mol] }\end{array}$} & \multirow[t]{2}{*}{$\begin{array}{l}D_{m} / \\
{\left[\mathrm{cm}^{2} / \mathrm{s}\right]}\end{array}$} & \multirow{2}{*}{$\begin{array}{l}\mathrm{f}_{\mathrm{n}}{ }^{\mathrm{a}} \\
\text { at } \mathrm{pH} 7.4\end{array}$} & \multicolumn{2}{|c|}{$\begin{array}{l}P_{\text {ion }} * f_{\text {ion }} /\left(P_{n} * f_{n}\right)^{b} \text { at } \\
\text { pH 7.4 }\end{array}$} \\
\hline & anion & neutral & & & & COSMOperm & $\begin{array}{l}\text { from } \\
K_{\text {hd/w }}\end{array}$ \\
\hline PFBA & -22.7 & -1.1 & 214.0 & $6.5 \mathrm{E}-07$ & $9.9 \mathrm{E}-08$ & $3.0 \mathrm{E}-02$ & $3.1 \mathrm{E}-03$ \\
\hline PFHxA & -20.9 & 0.4 & 314.1 & $5.5 \mathrm{E}-07$ & $1.6 \mathrm{E}-07$ & $9.0 \mathrm{E}-03$ & 5.7E-03 \\
\hline PFHpA & -20.3 & 1.1 & 364.1 & $5.1 \mathrm{E}-07$ & 1.7E-07 & $3.3 \mathrm{E}-03$ & $6.5 \mathrm{E}-03$ \\
\hline PFOA & -19.5 & 1.9 & 414.1 & 4.8E-07 & $1.4 \mathrm{E}-07$ & $2.6 \mathrm{E}-03$ & $1.2 \mathrm{E}-01$ \\
\hline PFNA & -18.8 & 2.6 & 464.1 & 4.6E-07 & $2.1 \mathrm{E}-07$ & 8.7E-04 & $1.5 \mathrm{E}-01$ \\
\hline PFDA & -18.1 & 3.3 & 514.1 & 4.0E-07 & $8.1 \mathrm{E}-08$ & $1.2 \mathrm{E}-03$ & $2.6 \mathrm{E}-01$ \\
\hline PFUnDA & -17.3 & 4.0 & 564.1 & $4.2 \mathrm{E}-07$ & $9.2 \mathrm{E}-08$ & $6.4 \mathrm{E}-04$ & $8.2 \mathrm{E}-01$ \\
\hline PFDODA & -16.7 & 4.7 & 614.1 & 4.0E- 07 & $2.8 \mathrm{E}-07$ & 2.65E-04 & 8.77E-01 \\
\hline HFPO-DA & -19.5 & 0.7 & 330.1 & $5.4 \mathrm{E}-07$ & $5.5 \mathrm{E}-07$ & $8.9 \mathrm{E}-03$ & $2.1 \mathrm{E}-02$ \\
\hline DONA & -19.6 & 1.4 & 378.1 & $5.0 \mathrm{E}-07$ & $3.8 \mathrm{E}-07$ & $2.2 \mathrm{E}-03$ & $1.1 \mathrm{E}-02$ \\
\hline \multicolumn{8}{|l|}{ PFSAs } \\
\hline PFBS & -18.9 & -0.9 & 300.1 & $5.6 \mathrm{E}-07$ & $8.4 \mathrm{E}-14$ & $4.4 \mathrm{E}+06$ & $2.8 \mathrm{E}+05$ \\
\hline PFHxS & -17.4 & 0.5 & 400.1 & $4.9 \mathrm{E}-07$ & $8.4 \mathrm{E}-14$ & $2.0 \mathrm{E}+06$ & 1.7E+06 \\
\hline PFOS & -15.9 & 2.0 & 500.1 & 4.4E- 07 & 7.9E-14 & $5.3 \mathrm{E}+05$ & $2.2 \mathrm{E}+07$ \\
\hline 9Cl-PF3ONS & -15.1 & 2.6 & 532.6 & 4.3E-07 & $6.9 \mathrm{E}-14$ & $4.4 \mathrm{E}+05$ & $6.1 \mathrm{E}+07$ \\
\hline PFECHS & -15.7 & 0.8 & 462.1 & 4.6E-07 & 2.3E-12 & $2.3 \mathrm{E}+05$ & $8.7 E+05$ \\
\hline
\end{tabular}

${ }^{a}$ Neutral fraction was calculated using the Henderson-Hasselbalch equation using the $\mathrm{pK}_{\mathrm{a}}$ predicted by COSMOtherm. Anionic fraction is $\sim 1$ due to low $p K_{\text {a }}$.

${ }^{\mathrm{b}}$ Relation between ionic and effective neutral permeability. If available, experimental anionic permeability was used, otherwise the permeability was predicted from the hexadecane/water partition coefficient. Neutral permeability was predicted using COSMOperm or from $K_{\mathrm{hd} / \mathrm{w}}$ respectively. 
Table S3.2.6. Literature data on the uptake of PFAAs. Stated are the compound, the uptake rate / clearance referenced to different units, the $\mathrm{pH}$ at which the experiment was done, the used cell type, and the calculated effective permeability $P_{\text {eff. }}$

\begin{tabular}{|c|c|c|c|c|c|c|}
\hline compound & $\begin{array}{l}\text { uptake rate/ } \\
{\left[\mathrm{nmol} / \mathrm{mg}_{\text {protein }} / \mathrm{min}\right]}\end{array}$ & $\begin{array}{l}\text { uptake clearance } / \\
{\left[\mu \mathrm{l} / \mathrm{mg}_{\text {protein }} / \mathrm{min}\right]}\end{array}$ & $\begin{array}{l}\text { uptake clearance }{ }^{b} / \\
{\left[\mu \mathrm{l} / 10^{6} \text { cells } / \mathrm{min}\right]}\end{array}$ & $\mathrm{pH}$ & cell type & $\begin{array}{l}P_{\text {eff }}{ }^{c} / \\
{[\mathrm{cm} / \mathrm{s}]}\end{array}$ \\
\hline PFHpA & $0.04^{d}$ & 4 & 0.4 & 7.4 & HEK293 & $1.6 \mathrm{E}-07$ \\
\hline PFOA & $0.13^{d}$ & 13 & 1.3 & 7.4 & HEK293 & $5.3 \mathrm{E}-07$ \\
\hline PFNA & $0.46^{d}$ & 46 & 4.5 & 7.4 & HEK293 & 1.9E-06 \\
\hline PFDA & $0.65^{d}$ & 65 & 6.4 & 7.4 & HEK293 & 2.7E-06 \\
\hline PFHpA & $0.09^{e}$ & 9 & 0.9 & 7.4 & HEK293 & 3.7E-07 \\
\hline PFOA & $0.10^{\mathrm{e}}$ & 10 & 0.98 & 7.4 & HEK293 & 4.1E-07 \\
\hline PFNA & $0.34^{\mathrm{e}}$ & 34 & 3.3 & 7.4 & HEK293 & 1.4E-06 \\
\hline PFDA & $0.30^{\mathrm{e}}$ & 30 & 2.9 & 7.4 & HEK293 & $1.2 \mathrm{E}-06$ \\
\hline PFOA & & $18.1^{f}$ & 1.8 & 6 & Caco-2 & 7.4E-07 \\
\hline PFOA & & & $67.8^{g}$ & 7.4 & $\begin{array}{l}\text { male rat } \\
\text { hepatocytes }\end{array}$ & $2.8 \mathrm{E}-05$ \\
\hline PFOA & & & $60.8^{\mathrm{g}}$ & 7.4 & $\begin{array}{l}\text { female rat } \\
\text { hepatocytes }\end{array}$ & $2.5 \mathrm{E}-05$ \\
\hline PFOA & & $20.6^{\mathrm{h}}$ & 2 & 6 & $\mathrm{CHO}$ & $8.4 \mathrm{E}-07$ \\
\hline PFOA & & $17.5^{\mathrm{h}}$ & 1.7 & 7.4 & $\mathrm{CHO}$ & 7.1E-07 \\
\hline \multicolumn{7}{|l|}{ PFSAs } \\
\hline PFBS & $0.033^{i}$ & 3.3 & 0.32 & 7.4 & HEK293 & 1.3E-07 \\
\hline PFHXS & $0.22^{i}$ & 22 & 2.2 & 7.4 & HEK293 & $9.0 \mathrm{E}-07$ \\
\hline PFOS & $1.10^{i}$ & 110 & 10.8 & 7.4 & HEK293 & 4.5E-06 \\
\hline PFBS & $0.018^{j}$ & 1.8 & 0.18 & 7.4 & $\mathrm{CHO}$ & 7.4E-08 \\
\hline PFHxS & $0.12^{\mathrm{j}}$ & 12 & 1.2 & 7.4 & $\mathrm{CHO}$ & 4.9E-07 \\
\hline PFOS & $0.81^{\mathrm{j}}$ & 81 & 7.9 & 7.4 & $\mathrm{CHO}$ & $3.3 \mathrm{E}-06$ \\
\hline
\end{tabular}

\footnotetext{
${ }^{a}$ If not stated directly in the literature, uptake clearance was calculated dividing the uptake rate by the concentration at which the experiment was done.

b If not stated directly in literature, uptake clearance per cell was calculated from uptake clearance per mg protein using the protein content for HEK293cells of $0.0098 \mathrm{mg} / 10^{5}$ cells in accordance with $\mathrm{Ng}$ and Hungerbuehler ${ }^{17}$. For all other cells, for simplicity the same value was applied.

${ }^{c}$ Effective permeability was calculated using a surface area for HEK293 cells of $4000 \mu \mathrm{m}^{2}$ estimated by $\mathrm{Ng}$ and Hungerbuehler ${ }^{17}$. For all other cells, for simplicity the same value was applied. The calculation is only valid if during the time of incubation the uptake rate can be assumed constant, and the concentration inside the cell is negligible in comparison to the external concentration.

d Uptake rate for PFAAs extracted from Fig. 3A in Weaver et al. ${ }^{18}$. Cells were control group with empty vector. Incubation time $1 \mathrm{~min}$ at $10 \mu \mathrm{M}$ PFAA concentration. Plots of the uptake against the incubation time show already saturation at 1 min, meaning
} 
the assumption of insignificant cytosolic concentration is already wrong at $1 \mathrm{~min}$. The uptake rates could thus be underestimated. Yet, they are alike to values measured after $10 \mathrm{~s}$ of incubation time (see footnote $\mathrm{h}$ ), so the error does not seem significant.

e Uptake rate for PFAAs extracted from Fig. 8B in Zhao et al. ${ }^{19}$ Cells were control group with empty vector. Incubation time 1 min at $10 \mu \mathrm{M}$ PFAA concentration.

${ }^{f}$ From Kimura et al. ${ }^{20}$; incubation time 1 min.

${ }^{\mathrm{g}}$ From Han et al. ${ }^{21}$. Incubation time $30 \mathrm{~s}$.

${ }^{\mathrm{h}}$ From Yang et al. ${ }^{22}$. Incubation time $10 \mathrm{~s}$. Cells were control group with empty vector.

' Uptake rate for PFAAs extracted from Fig. 2A in Zhao et al. ${ }^{19}$. Cells were control group with empty vector. Incubation time 1 min at $10 \mu \mathrm{M}$ PFAA concentration.

${ }^{\mathrm{j}}$ Uptake rate for PFAAs extracted from Fig. 5A in Zhao et al. ${ }^{19}$. Cells were control group with empty vector. Incubation time 1 min at $10 \mu \mathrm{M}$ PFAA concentration. 
Table S3.2.7. Compound, $\mathrm{pH}$ used for calculations, effective anionic $P_{\text {eff,ion }}$ or neutral $P_{\text {eff, } n}$ permeability, and range of effective permeability $P_{\text {eff,lit }}$ from literature listed in Table S3.2.6. exp: experimental, pred: predicted.

\begin{tabular}{|c|c|c|c|c|c|c|}
\hline \multirow[t]{2}{*}{ compound } & \multirow[t]{2}{*}{$\mathrm{pH}$} & \multicolumn{2}{|c|}{$P_{\text {,eff,ion }}{ }^{\mathrm{a}} /[\mathrm{cm} / \mathrm{s}]$} & \multirow{2}{*}{$\begin{array}{l}P_{\text {eff, } \mathrm{n}} /[\mathrm{cm} / \mathrm{s}] \\
\left(P_{\mathrm{n}}, \text { pred }, \mathrm{pH}\right)^{\mathrm{d}}\end{array}$} & \multirow{2}{*}{$\begin{array}{l}\left(P_{\text {eff,n }} / 10^{-1.8}\right) /[\mathrm{cm} / \mathrm{s}] \\
-1.8 \log \text { units }^{\mathrm{e}}\end{array}$} & \multirow{2}{*}{$\begin{array}{l}\boldsymbol{P}_{\text {eff,lit }} /[\mathrm{cm} / \mathrm{s}] \\
\text { range }\end{array}$} \\
\hline & & $\begin{array}{l}\left(\Delta \mathrm{V}, P_{\text {ion, }}\right. \\
\text { exp, } \mathrm{pH})^{\mathrm{b}}\end{array}$ & $\begin{array}{l}\left(\Delta \mathrm{V}, P_{\text {ion }}\right. \\
\text { pred, } \mathrm{pH})^{\mathrm{c}}\end{array}$ & & & \\
\hline \multicolumn{7}{|l|}{ PFCAs } \\
\hline PFHpA & 7.4 & & $9.8 \mathrm{E}-09$ & $1.2 \mathrm{E}-05$ & $1.9 \mathrm{E}-07$ & 1.6E-07 - 3.7E-07 \\
\hline PFOA & 7.4 & $1.6 \mathrm{E}-07$ & $3.2 \mathrm{E}-08$ & $5.0 \mathrm{E}-05$ & $7.9 \mathrm{E}-07$ & $4.1 \mathrm{E}-07-2.8 \mathrm{E}-05$ \\
\hline PFNA & 7.4 & $4.0 \mathrm{E}-07$ & 8.0E-08 & 3.7E-04 & $5.9 \mathrm{E}-06$ & $1.4 \mathrm{E}-06-1.9 \mathrm{E}-06$ \\
\hline PFDA & 7.4 & & $2.1 \mathrm{E}-07$ & 7.1E-04 & $1.1 \mathrm{E}-05$ & $1.2 \mathrm{E}-06-2.7 \mathrm{E}-06$ \\
\hline PFOA & 6.0 & $1.6 \mathrm{E}-07$ & $3.2 \mathrm{E}-08$ & $1.3 \mathrm{E}-03$ & $2.0 \mathrm{E}-05$ & $7.4 \mathrm{E}-07-8.4 \mathrm{E}-07$ \\
\hline PFOA & 7.0 & $1.6 \mathrm{E}-07$ & $3.2 \mathrm{E}-08$ & $1.3 \mathrm{E}-04$ & $2.0 \mathrm{E}-06$ & \\
\hline PFOA & 8.0 & $1.6 \mathrm{E}-07$ & $3.2 \mathrm{E}-08$ & $1.3 \mathrm{E}-05$ & $2.0 \mathrm{E}-07$ & \\
\hline \multicolumn{7}{|l|}{ PFSAs } \\
\hline PFBS & 7.4 & $5.1 \mathrm{E}-08$ & $6.8 \mathrm{E}-08$ & $5.9 \mathrm{E}-14$ & $9.3 \mathrm{E}-16$ & $7.4 \mathrm{E}-08-1.3 \mathrm{E}-07$ \\
\hline PFHxS & 7.4 & $1.0 \mathrm{E}-06$ & $6.0 \mathrm{E}-07$ & $1.2 \mathrm{E}-12$ & $1.9 \mathrm{E}-14$ & $4.9 \mathrm{E}-07-9.0 \mathrm{E}-07$ \\
\hline PFOS & 7.4 & $1.4 \mathrm{E}-05$ & 4.5E-06 & $3.5 \mathrm{E}-11$ & $5.5 \mathrm{E}-13$ & $3.3 \mathrm{E}-06-4.5 \mathrm{E}-06$ \\
\hline
\end{tabular}

\footnotetext{
${ }^{a}$ Effective permeability for the anionic species was determined by calculating the ionic flux per concentration from the exterior into the cytosol using Eq. S7 (the concentration in the cytosol is thereby assumed 0). As the fraction of the ionic species is 1 in all our calculations, the only factor that distinguishes the effective ionic permeability from ionic permeability is the influence of the potential gradient of $-60 \mathrm{mV}$ across the membrane.

${ }^{b}$ Effective permeability for the anionic species calculated from the experimental permeability value, an assumed potential of $-60 \mathrm{mV}$, and an anion fraction of 1 .

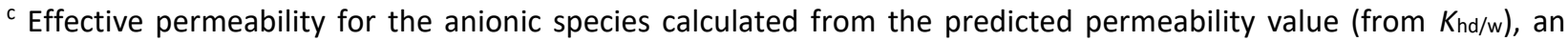
assumed potential of $-60 \mathrm{mV}$, and an anion fraction of 1 .

${ }^{d}$ Effective permeability for the neutral species calculated from the predicted permeability value (from $\left.K \mathrm{hd} / \mathrm{w}\right)$. Neutral permeability was multiplied with the neutral fraction that was calculated with the $\mathrm{pK}_{\mathrm{a}}$ values computed with cosMOtherm.

e To account for the observation that permeabilities of the neutral species in CACO-2 cells seem to be about 1.8 orders of magnitude lower than in artificial bilayer measurements, likely due to their content in sphingomyelin and cholesterol, $P_{\text {eff,n }}$ was divided by $10^{-1.8}$ to provide a constant shift of 1.8 log units.
} 
Table S3.2.8. Compound, $\mathrm{pH}$ used for calculations, relation between $P_{\text {eff }}$ at various $\mathrm{pH}$ values and $\mathrm{P}_{\text {eff }}$ at $\mathrm{pH}$, for literature data and stated calculations.

\begin{tabular}{|c|c|c|c|c|}
\hline \multirow[t]{2}{*}{ compound } & \multirow[t]{2}{*}{$\mathrm{pH}$} & \multirow[t]{2}{*}{$\boldsymbol{P}_{\text {eff,lit }} / \boldsymbol{P}_{\text {eff,lit }}(\mathrm{pH} 6)^{\mathrm{a}}$} & \multicolumn{2}{|c|}{$P_{\text {eff }} / P_{\text {eff }}(\mathrm{pH} 6)^{\mathrm{b}}$} \\
\hline & & & based on $P_{\text {eff,n }} / 10^{-1.8}$ & based on $\left(P_{\text {eff, }} / 10^{-1.8}\right) / 300$ \\
\hline PFOA & 6 & $100 \%$ & $100 \%$ & $100 \%$ \\
\hline PFOA & 7 & $77 \%$ & $11 \%$ & $74 \%$ \\
\hline PFOA & 8 & $67 \%$ & $2 \%$ & $71 \%$ \\
\hline
\end{tabular}

a PFOA uptake [radioactive disintegrations per minute per well] in HEK293 cells, extracted from Fig. 1B in Yang et al. ${ }^{22}$. Percentages were calculated by dividing the uptake rates at $\mathrm{pH}$ 6-8 by the uptake rate at $\mathrm{pH} 6$.

${ }^{b}$ Percentages were calculated by dividing $P_{\text {eff }}$ of PFOA at $\mathrm{pH}$ 6-8 by $P_{\text {eff }}$ at $\mathrm{pH}$ 6. Thereby, $P_{\text {eff }}$ was calculated as the

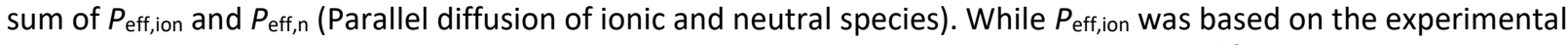
artificial bilayer permeability value (see Table S3.2.7), for $P_{\text {eff, } n}$ was either used $P_{\text {eff, }} / 10^{-1.8}$ (shift to compensate for possible differences between artificial bilayer and biomembranes) as stated in Table S3.2.7, or $P_{\text {eff, },} / 10^{-1.8} / 300$ (additional shift to compensate for a possible overestimation in $P_{\mathrm{n}}$ or $\mathrm{pK}_{\mathrm{a}}$ ), respectively. 


\section{S4 References}

1. Howard, P. H.; Muir, D. C., Identifying new persistent and bioaccumulative organics among chemicals in commerce. Environ. Sci. Technol. 2010, 44, (7), 2277-2285.

2. De Silva, A. O.; Spencer, C.; Scott, B. F.; Backus, S.; Muir, D. C., Detection of a cyclic perfluorinated acid, perfluoroethylcyclohexane sulfonate, in the Great Lakes of North America. Environ. Sci. Technol. 2011, 45, (19), 8060-8066.

3. Chen, F.; Yin, S.; Kelly, B. C.; Liu, W., Chlorinated Polyfluoroalkyl Ether Sulfonic Acids in Matched Maternal, Cord, and Placenta Samples: A Study of Transplacental Transfer. Environ Sci Technol 2017, 51, (11), 6387-6394.

4. Dodge, J. T.; Phillips, G. B., Composition of phospholipids and of phospholipid fatty acids and aldehydes in human red cells. J. Lipid Res. 1967, 8, 667-675.

5. Henneberger, L.; Goss, K. U.; Endo, S., Equilibrium Sorption of Structurally Diverse Organic lons to Bovine Serum Albumin. Environ. Sci. Technol. 2016, 50, (10), 5119-5126.

6. Endo, S.; Goss, K. U., Serum albumin binding of structurally diverse neutral organic compounds: data and models. Chem. Res. Toxicol. 2011, 24, (12), 2293-2301.

7. Ebert, A.; Hannesschlaeger, C.; Goss, K. U.; Pohl, P., Passive Permeability of Planar Lipid Bilayers to Organic Anions. Biophys. J 2018, 115, (10), 1931-1941.

8. Bittermann, K.; Spycher, S.; Endo, S.; Pohler, L.; Huniar, U.; Goss, K. U.; Klamt, A., Prediction of Phospholipid-Water Partition Coefficients of Ionic Organic Chemicals Using the Mechanistic Model COSMOmic. J. Phys. Chem. B 2014, 118, (51), 14833-14842.

9. Eckert, F.; Klamt, A., Fast solvent screening via quantum chemistry: COSMO-RS approach. AlChE J. 2002, 48, (2), 369-385.

10. Avdeef, A., Leakiness and size exclusion of paracellular channels in cultured epithelial cell monolayers-interlaboratory comparison. Pharm. Res. 2010, 27, (3), 480-9.

11. Bittermann, K.; Goss, K. U., Predicting apparent passive permeability of Caco-2 and MDCK cellmonolayers: A mechanistic model. PLoS One 2017, 12, (12), e0190319.

12. Droge, S. T. J., Membrane-water partition coefficients to aid risk assessment of perfluoroalkyl anions and alkyl sulfates. Environ. Sci. Technol. 2018, 53, 760-770.

13. Baumer, A.; Bittermann, K.; Klüver, N.; Escher, B. I., Baseline toxicity and ion-trapping models to describe the $\mathrm{pH}$-dependence of bacterial toxicity of pharmaceuticals. Environ. Sci.: Processes Impacts 2017, 19, (7), 901-916.

14. COSMOconf (V 4.1), COSMOlogic GmbH \& Co KG, http://www.cosmologic.de.

15. TURBOMOLE 4.2.1 (2016), a development of University of Karlsruhe and Forschungszentrum Karlsruhe GmbH, 1989-2007, TURBOMOLE GmbH, since 2007: available from http://www.turbomole.com.

16. Allendorf, F.; Berger, U.; Goss, K.-U.; Ulrich, N., Partition coefficients of four perfluoroalkyl acid alternatives between bovine serum albumin (BSA) and water in comparison to ten classical perfluoroalkyl acids. Environ. Sci.: Processes Impacts 2019, 21, 1852-1863

17. Ng, C. A.; Hungerbühler, K., Bioconcentration of perfluorinated alkyl acids: how important is specific binding? Environ Sci Technol 2013, 47, (13), 7214-7223.

18. Weaver, Y. M.; Ehresman, D. J.; Butenhoff, J. L.; Hagenbuch, B., Roles of rat renal organic anion transporters in transporting perfluorinated carboxylates with different chain lengths. Toxicol. Sci. 2010, $113,(2), 305-314$.

19. Zhao, W.; Zitzow, J. D.; Weaver, Y.; Ehresman, D. J.; Chang, S. C.; Butenhoff, J. L.; Hagenbuch, B., Organic Anion Transporting Polypeptides Contribute to the Disposition of Perfluoroalkyl Acids in Humans and Rats. Toxicol. Sci. 2017, 156, (1), 84-95. 
20. Kimura, O.; Fujii, Y.; Haraguchi, K.; Kato, Y.; Ohta, C.; Koga, N.; Endo, T., Uptake of perfluorooctanoic acid by Caco-2 cells: Involvement of organic anion transporting polypeptides. Toxicol. Lett. 2017, 277, 18-23.

21. Han, X.; Yang, C. H.; Snajdr, S. I.; Nabb, D. L.; Mingoia, R. T., Uptake of perfluorooctanoate in freshly isolated hepatocytes from male and female rats. Toxicol. Lett. 2008, 181, (2), 81-86.

22. Yang, C. H.; Glover, K. P.; Han, X., Characterization of cellular uptake of perfluorooctanoate via organic anion-transporting polypeptide $1 \mathrm{~A} 2$, organic anion transporter 4 , and urate transporter 1 for their potential roles in mediating human renal reabsorption of perfluorocarboxylates. Toxicol. Sci. 2010, 117, (2), 294-302. 